\title{
Hydroxypyrene Excretion as Indicator of Cancer Risk in Street Sweepers and Polycyclic Aromatic Hydrocarbons (Pahs) Exposure
}

\author{
Mazzotta $M^{1 *}$, Mazzotta $A D^{2}$, d'Ettorre $G^{3}$, Cazzato $R G^{3}$, Simone $C^{4}$ and Fernandez $M^{1}$
}

${ }^{1}$ Prevention and protection service safety and Health University of Salento, Italy

${ }^{2}$ University of Roma Tor Vergata faculty of medicine, Rome, Italy

${ }^{3}$ Occupational medicine service, Italy

${ }^{4}$ University of Bari bachelor laboratory technicians, Italy

*Corresponding author: Mazzotta M, Prevention and protection service safety and Health University of Salento, 73100 Lecce, Italy, E-mail: mazzotta.mauro@libero.it

\begin{abstract}
Exposure to polycyclic aromatic hydrocarbons (PAHs) is associated with possible carcinogenicity, according to European directives Studies helped to clarify the contributions to the total dose resulting from environmental and occupational exposure, by tobacco smoke, by diet and skin absorption. Recently, it was shown that levels of 1-Hydroxypyrene $\mathrm{U}$ (1-OHPu) may be predictive of individual dose, environmental and employment exposure, proportionately even though indirectly expressing the concentration of Benzo[a]pyrene (Bap) and of pyrene (Pyr), too, since the latter is associated to Bap with stable proportionality. The 1-OHPu, metabolite of Pyr, which proved to be mutagen for photochemical effect, can be considered the better indicator of internal dose not only for recent exposure, but also as an indicator of accumulation and diffusion in the human body, given the greater solubility in water of Pyr compared to Bap. Moreover, it is more sensitive than 3-Hydroxybenzo[a] pyrene (3-OHBaP) for the estimation of total exposure to PAHs. Measurements of the concentration of $1-\mathrm{OHPu}$ in the urinary excretions of street sweepers at the end of their daily working period showed an increase of the 1-OHPu geometric mean concentration both forever smokers - never smoking and/or selectively affected by chronic bronchitis (all smokers). These workers are exposed in the urban environment to pollution due to diesel engines, domestic heating and industrial PAHs emissions from petrol and coal combustion in power stations. The continuous increase of the number of workers affected by bronchitis ask for experimental studies to test the ability of Pyr to remain in the epithelium and in subbronchial epithelium, apparently to a greater extent for its greater dilution in the inflamed tissue, slowing down its biotransformation in water-soluble metabolites. In this way, a reserve of pre-toxic $\mathrm{PAHs}$ accumulates at pulmonary level and determines a stronger urinary elimination of $1-\mathrm{OHPu}$. The presence of $1-\mathrm{OHP}$ in urinary excretions is, then, an indicator of PAHs exposure.
\end{abstract}

Evidence of ILCR (incremental life-time cancer risk) is demonstrated in association with ambient Bap concentration, smoke and chronic bronchitis vs. control group (ILCR inhalation $_{\text {range }}$, 6-9, $13 \times 10^{-6}$ ), and a historical similarity with chimney sweepers is remembered.

\section{Abbreviations}

CYP: Cytochrome P450, 1-OHPu: Urinary 1-hydroxypyrene; PAHs: Polycyclic aromatic hydrocarbons, PYR: Pyrene, Bap: Benzo[a] pyrene, ILCRinhalation: Incremental lifetime cancer risk inhalation, CSF: Cancer slope factor, Searly: Early shift, Send: End shift.

\section{Introduction}

It is well known that exposure to PAHs like Dibenzo(a,h) anthracene (DBA), Benzo(a)pyrene (BaP), Pyrene (Pyr), Benzo(a) anthracene $(\mathrm{BaA}), \quad \operatorname{Benzo}(\mathrm{b}, \mathrm{j}, \mathrm{k})$ fluoranthene $(\mathrm{BbF}), \quad \operatorname{Benzo}(\mathrm{k})$ fluoranthene (Bkf) is bound to possible carcinogenicity, as highlighted in the statements of phrases R45/R49/H350 according to European directives [1-4]. The concentration of PAHs in the respiratory system increases with age (e.g., for $\mathrm{BaP}, \mathrm{BkF}$ ) according to the diagram men $>$ women, smokers $>>$ never-smokers, cancerogenous lung cells $>$ not cancerogenous ones [5]. On the other hand, the liver ability to proceed to biotransformation by cytochrome 4501A1, activates in many cases the same toxicity and carcinogenesis. So, if the same PAHs are the major air pollutants as a result of combustion processes, many data indicate in the feeding and gastro-enteric tract an additional quota of dose, because, although they are lipophilic compounds, some of them are present in varying concentrations in water and in various types of food, including vegetables [6,7], US-EPA, SCF, JECFA classification of PAHs pollution in environment and food [6].

The study of DNA polymorphisms of genes like CYP1A1, GSTM1, mEH, GSTP1 and GSTT1 clarified that individual variability in levels of 1-OHPu is a consequence of higher metabolic capacity in "CYP1A1 Ile/Val genotype" and "GSTM1 null genotype" individuals: in children CYP1A1 and CYP1B1, NQO1 (activation) and GSTM (disable) are identified [8,9]. Many environmental factors, such as temperature, light, oxygen, ozone and pollutant concentrations, oxidation, photochemical reactions with $\mathrm{NO}_{2}, \mathrm{SO}_{2}$ and $\mathrm{SO}_{3}$, influence the chemical reactivity. Bioavailability is an important factor to determine the possibility that a higher or lower quantity of PAHs enter into cellular systems. For instance, PAHs present in the vapor phase (e.g., gas from coke-fuelled ovens), is of high bioavailability, while PAHs from urban environments (heating, transport) is not [10] However, given the difficulty of estimating the total "intake/ uptake" from the air (environment/employment/exposure smoke), diet intake and skin absorption, the best choice for assessing the total exposure to PAHs is a biomarker study. We have taken into account that 1-OHP, although not specific to genotoxicity like 3-OHBap [11], can be chosen as a good indicator of internal exposure dose not only for PAHs (since it is the metabolite of Pyr, which among PAHs is the

\section{Clinmed} International Library

Citation: Mazzotta M, Mazzotta AD, d'Ettorre G, Cazzato RG, Simone C, et al. (2015) Hydroxypyrene Excretion as Indicator of Cancer Risk in Street Sweepers and Polycyclic Aromatic Hydrocarbons (Pahs) Exposure. J Toxicol Risk Assess 1:002

Received: November 02, 2015: Accepted: December 12, 2015: Published: December 16, 2015 Copyright: ( 2015 Mazzotta M, et al. This is an open-access article distributed under the terms of the Creative Commons Attribution License, which permits unrestricted use, distribution, and reproduction in any medium, provided the original author and source are credited. 
chemical compound more representative and more diffused in the urban and working environment and represents $90 \%$ of the urinary excretion) even for different categories of persons [12-14]. It may be a sign of greater exposure to different risk stratifications, with urinary concentrations up to 2500 times higher than the $3-\mathrm{OHBaP}$ $(12,16.17)$. It is also useful compared to Pyr, which is able to become mutagenic after exposition to sunlight [Pyrene (84) $12900--0++$ $8926 \pm 3111205 \pm 42(0.03)$ Bacteria death] [15]. In this sense, we cannot exclude the synergy with the most powerful carcinogens and in particular with Bap [6]. Keeping also into account that Pyr, for its water solubility characteristics $\left(7.2 \times 10^{-4} \mathrm{mmol} / \mathrm{l}\right)$, is able to pass through the lung into the blood and undergo biotransformation, Pyr solubility has to be compared to the one of Bap $\left(1.5 \times 10^{-5} \mathrm{mmol} / \mathrm{l}\right)$, about 48 times lower. Moreover, the latter presents a vapor density of $8.4 \times 10^{-7}$, about thousand times lower than that of Pyr, which is 8.86 $\times 10^{-4}$. Then $1-\mathrm{OHPu}$ can be considered as a better predictive model of PAHs concentration in different conditions of risk. A lifetime risk of respiratory cancer per $\mathrm{ng} / \mathrm{m}^{3}$ was calculated $[16,17]$

\section{Materials and methods}

In this study we evaluated the urinary excretion of 1-OHPu in 31 healthy "street sweepers" and in 8 with a bronchitis process all smokers, exposed mainly to urban and industrial air pollution (they use semiautomatic systems to empty garbage road containers and/or manually collect bags with materials for recycling, but the exposure is also due to fumes from diesel engine combustion and to other environmental pollutants in areas where the production of PAHs is due to the operation of coal-fired power stations, lime furnaces, petrochemical candles, combustion of part of olive trees - Salento country), as an indicator of internal dose for exposure to fumes from the combustion of diesel and internal combustion engines, but also of domestic heating systems and industrial emissions of PAHs from petrochemical factories and coal-fuelled power stations) [18]. All the
39 "street sweepers", living in the same operational area (Brindisi-Italy), were male. Among the healthy (non bronchitic) "street sweepers", the smokers were found to be $12(26 \%)$. For every worker the $1-\mathrm{OHPu}$ urinary concentration was measured in samples collected at the beginning and at the end of their working periods for at least three consecutive days of work. The measurements were made by using the method of Jongeneelen (1987) [19], after enzymatic hydrolysis of $ß$-glucuronides and/or sulphate conjugates, followed by analysis using high-performance liquid chromatography (HPLC), combined with a fluorimetric detector. The limit of detection of the method is $25 \mathrm{ng} / \mathrm{l}$. The concentrations of urinary $1-\mathrm{OHPu}$ were expressed in $\mathrm{ng} / \mathrm{g}$ creatinine.

\section{Results}

Environmental exposure values are reported in table 1. The geometric averages of the measured 1-OHPu concentration values are shown in table 2 and table 3 , and histograms in figure 1, figure 2 and figure 3.The above values were compared with the ones of a group of 18 workers involved in indoor activities, in order to evaluate the usefulness of 1-OHPu assay as part of health monitoring processes. In figure 4 is reported $\mathrm{ILCR}_{\text {inhalation }}$ in PAHs exposure and in figure 5 the same data on a logarithmic scale.

The concentration values associated to never smokers (NS) and forever smokers (S) and exposure (years) are shown in table 2 and figure 2 , at the beginning and end of working shift.

ILCR calculated by PAHs exposure with benzo[a]pyrene concentration expressed in $\mathrm{ng} / \mathrm{m}^{3}$ ILCR $=\left\{\mathrm{C}_{\mathrm{a}}\left[\mathrm{CSF}(\mathrm{BW} / 70)^{1 / 3}\right]\right.$ dayyear ${ }^{-1} \cdot$ year $\left./ \mathrm{BW} \cdot \mathrm{AT}\right\} \cdot \mathrm{C}_{\mathrm{f}}[20,21]$ where:

ILCR is incremental life-time cancer risk [22]

$\mathrm{C}_{\mathrm{a}}$ is PAH concentration as Bap $\mathrm{ng} / \mathrm{m}^{3}$ in working shift

$\operatorname{CSF}(3,1)$ is cancer slope factor $\mathrm{ng} / \mathrm{m}^{3}\left(\mathrm{WHO}_{24}\right) ;\left(\mathrm{mgKg}^{-1} \mathrm{day}^{-1}\right)^{-1}$ U.S.EPA, 2001

Table 1: Environmental exposure value.

\begin{tabular}{|l|l|l|l|l|}
\hline \multicolumn{2}{|l|}{ Total PAH } & Benzo[a]pirene & \multicolumn{2}{l|}{ PM10 } \\
\hline $\mathrm{ng} / \mathrm{m}^{3}$ & Total ng/exposed person/working shift & $\mathrm{ng} / \mathrm{m}^{3}$ & $\begin{array}{l}\text { ng"intake"/exposed person/working } \\
\text { period }\end{array}$ & $\mu \mathrm{\mu g} / \mathrm{exposed}$ person/working period \\
\hline $33-75$ & $495-1125$ & $0.089-0.55$ & $1.33-8.25$ & 450 \\
\hline
\end{tabular}

Table 2: $10 \mathrm{HP}_{\mathrm{u}}$ shift $_{\text {early }}$ never smokers $\left(\mathrm{S}_{\text {early }} \mathrm{NS}\right)$ and smokers $\left(\mathrm{S}_{\text {early }} \mathrm{S}\right)$ and Shift $_{\text {end }}$ never smokers $\left(\mathrm{S}_{\text {end }} \mathrm{NS}\right)$ and $\mathrm{Shift}$ end $\mathrm{Smokers}\left(\mathrm{S}_{\text {end }} \mathrm{S}\right)-\mathrm{t}$-test $\left(^{*}\right)$.

\begin{tabular}{|c|c|c|c|c|c|c|}
\hline $\begin{array}{l}\text { Table } 1 \\
\text { Risk }\end{array}$ & Smoke & $\mathbf{N}^{\circ}$ & Geom.-mean ng/gr creat & -DS & +DS & \\
\hline \multirow{2}{*}{$\begin{array}{l}\text { Exposed } \\
\text { Shift }_{\text {early }}\end{array}$} & NS & 19 & 316 & 158 & 630 & \\
\hline & S & 12 & 1000 & 398 & 2511 & $\mathrm{P}<.001$ vs. NS and contra NS $\left(^{*}\right)$ \\
\hline \multirow{2}{*}{$\begin{array}{l}\text { Exposed } \\
\text { Shift }_{\text {end }}\end{array}$} & ES-NS & 19 & 1259 & 398 & 3989 & $\mathrm{P}<.001$ vs NF I T $\left(^{*}\right)$ \\
\hline & ES-S & 12 & 1981 & 629 & 6237 & $\mathrm{P}<.001$ vs NF IT $\left(^{*}\right)$ \\
\hline Control non exposed & NS & 9 & 230 & 103 & 513 & \\
\hline
\end{tabular}

Table 3: Concentration of 1-OHP , associated to exposure(y) in never smokers (NS) and forever smokers (S), at the beginning $\left(\mathrm{S}_{\text {early }}\right)$ and end $\left(\mathrm{S}_{\text {end }}\right)$ of working shift -t-test $\left(^{*}\right)$

\begin{tabular}{|c|c|c|c|c|c|c|}
\hline Risk exposure (y) & Shift/Smoke & $\mathbf{N}^{\circ}$ & Geom.mean ng/gr creat & -DS & +DS & \\
\hline \multirow{2}{*}{$\begin{array}{l}\text { Exposed }<15 \\
\text { Exposed }>15\end{array}$} & $\mathrm{~S}_{\text {early }} \mathrm{NS}$ & 10 & 251 & 158 & 398 & \\
\hline & $\mathrm{S}_{\text {early }} \mathrm{NS}$ & 9 & 436 & 173 & 1096 & \\
\hline \multirow{2}{*}{$\begin{array}{l}\text { Exposed }<15 \\
\text { Exposed }>15\end{array}$} & $\mathrm{~S}_{\text {end }} \mathrm{NS}$ & 10 & 1071 & 446 & 2570 & \\
\hline & $\mathrm{S}_{\text {end }} \mathrm{NS}$ & 9 & 1031 & 333 & 3184 & \\
\hline \multirow{2}{*}{$\begin{array}{l}\text { Exposed }<15 \\
\text { Exposed }>15\end{array}$} & $\mathrm{~S}_{\text {early }} \mathrm{S}$ & 8 & 794 & 316 & 1995 & \\
\hline & $\mathrm{S}_{\text {early }} \mathrm{S}$ & 4 & 1000 & 254 & 3987 & \\
\hline \multirow{2}{*}{$\begin{array}{l}\text { Exposed }<15 \\
\text { Exposed }>15\end{array}$} & $\mathrm{~S}_{\text {end }} \mathrm{S}$ & 8 & 1995 & 501 & 7761 & $\mathrm{P}<0.01$ comparing $\mathrm{y}<15-\mathrm{y}>15 \mathrm{NSS}_{\text {early }}\left({ }^{*}\right)$ \\
\hline & $\mathrm{S}_{\text {end }} \mathrm{S}$ & 4 & 1584 & 316 & 7913 & \\
\hline \multirow{2}{*}{$\begin{array}{l}\text { Exposed broncostr. } \\
\text { all smokers }\end{array}$} & $S_{\text {early }} \mathrm{S}$ & 8 & 1412 & 870 & 2290 & \\
\hline & $\mathrm{S}_{\text {end }} \mathrm{S}$ & 8 & 2137 & 1513 & 3019 & $\mathrm{P}<0.01$ comparing $\left.\mathrm{y}<15-\mathrm{y}>15 \mathrm{NS} \mathrm{S}_{\text {early }}{ }^{*}\right)$ \\
\hline \multirow{2}{*}{ Smokers $<15$ s } & $\mathrm{S}_{\text {early }}$ & 4 & 1819 & 1713 & 1931 & \\
\hline & $\mathrm{S}_{\mathrm{end}}$ & 4 & 3133 & 824 & 11712 & \\
\hline \multirow{2}{*}{ Smokers $>15 \mathrm{~s}$} & $\mathrm{~S}_{\text {early }}$ & 8 & 794 & 316 & 1995 & \\
\hline & $\mathrm{S}_{\text {end }}$ & 8 & 1584 & 501 & 5011 & \\
\hline
\end{tabular}




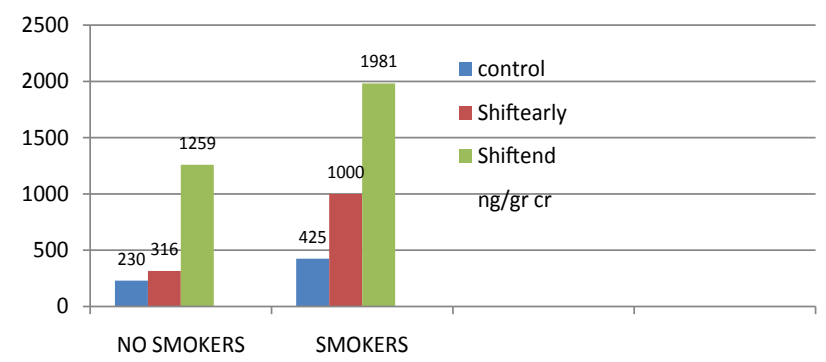

Figure 1: $\left[1-\mathrm{OHP}_{\mathrm{u}}\right.$ concentration (ng/g creatinine)] at the beginning (shift ${ }_{\text {early }}$ ) and at the end (shift ${ }_{\text {end }}$ ) of the working shift for no smokers and smokers.

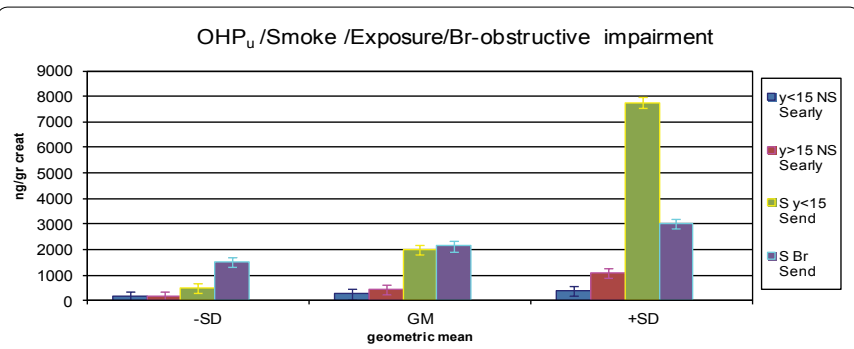

Figure 2: 1-OHP ${ }_{u}$ concentration in never smokers early shift exposure $<15$ years $\left(y<15 N \mathrm{NS}_{\text {early }}\right)$ never smokers early shift exposure $>15$ years $(y>15$ NS $\left.S_{\text {early }}\right)$, smokers $<15$ y $S_{\text {end }}\left(S_{\text {end }}\right)$, bronchitis illness.

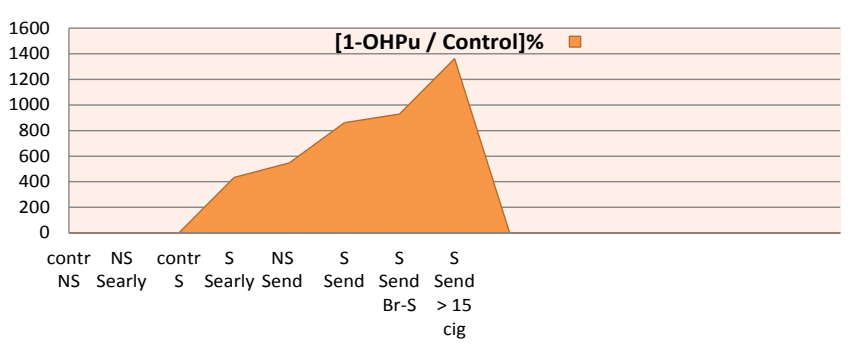

Figure 3: $\left[1-\mathrm{OHP}_{u}\right]$ in $\mathrm{PAH}$ exposure / $\left[1-\mathrm{OHP}_{u}\right]$ Controls \% in workers groups: NS: Never smokers, S: Forever smokers, Shift early and Shift ${ }_{\text {end }}$ Br-S: Bronchitic smokers

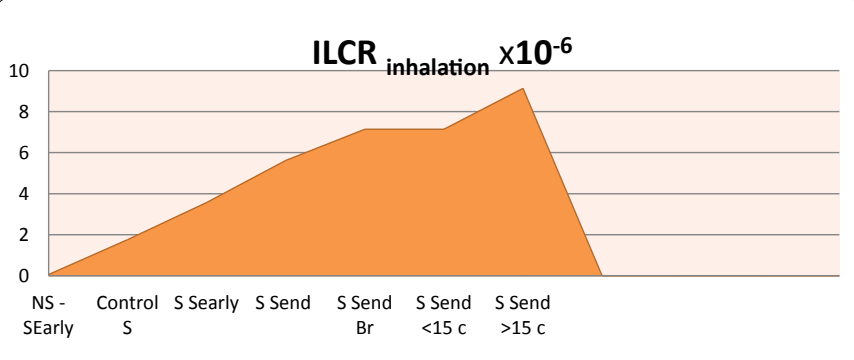

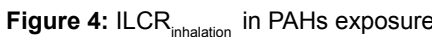

BW = body weight $(75 \mathrm{Kg})$

40 year of life in work

Dayyear $^{-1}$ - days of work for year of work exposure (210)

$\mathrm{AT}=$ average time in work (40)

$\mathrm{C}_{\mathrm{f}}=10^{-6}$

For evaluating risks from inhalation exposure, $\mathrm{MDH}$ recommends a Health Risk Value (HRV) of $0.001 \mathrm{ng} / \mathrm{m}^{3}$ for B[a]P [23], which is based on a slope factor of $7.3(\mathrm{mg} / \mathrm{kg} \text {-day })^{-1}$. This slope factor is the geometric mean of the $\mathrm{B}[\mathrm{a}] \mathrm{P}$ slope factor range used by the U.S. Environmental Protection Agency (U.S. EPA, 2001).

The geometric mean concentration of $1-\mathrm{OHPu}$ among the exposed workers at beginning of their working shift is greater in forever smokers (S) than for never smokers (NS) and for never smokers controls (control NS). But, the most significant data is that the exposed workers, both never smokers and forever smokers, at the end of their working shift $\left(\mathrm{S}_{\text {end }} \mathrm{NS}\right.$ : $\mathrm{S}_{\text {end }} \mathrm{S}$ ) show higher 1-OHP

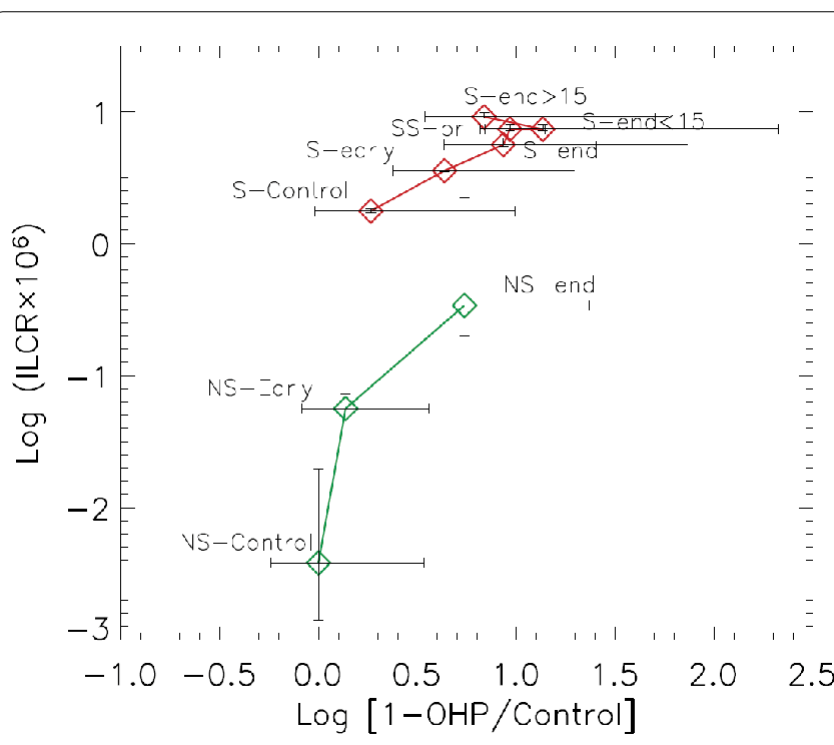

Figure 5: ILCR $\mathrm{Iinhalation}_{\text {in }} \mathrm{PAHs}$ exposure expressed on a logarithmic scale

concentration values than that of the same workers at the beginning of their working shift and of the control non-exposed workers. Tables and figures also demonstrate the smoke influence, associated with the exposure, i.e. the greater values of urinary excretion of $1-\mathrm{OHPu}$ against the ones of never-smokers. More, the 1-OHP concentration is significantly higher in forever smokers with more than 15 years of exposure, than in never smokers at the beginning of their working shift $\left(\mathrm{S}_{\text {early }} \mathrm{NS}\right)$. Cigarette smoke factor is significant for smokers in conjunction with less than 15 years of exposure at the end of working shift ( $\mathrm{S}$ end shift $<15 \mathrm{y}$ exposure), as well as for the control group. The same happens for those with bronchial obstructive impairment.

In general $1-\mathrm{OHP}_{\mathrm{u}}$ concentration behaves as an interesting variable, associated not only to recent exposure, but also to the effects of accumulation, since the increase in concentration is influenced by the years of exposure as well as by unhealthy breathing ways, likely to inflammation and edema accumulation.

As regards the application of preventive rules, the characteristics of smoking behavior are to be studied. Behaviors depend on the technology used by the worker. Sweepers attached to the moving medium with hook switch of dumpsters to the moving car, can hardly smoke during the service period, but they can smoke very much, assuming the related risk, at the beginning and end of their workday.

\section{Discussion}

Our study showed an increase in the urinary excretion of 1-OHP at end of working shift with respect to the one at the beginning, in smokers and never smokers and in suffering from chronic bronchitis, exposed to pollution sources such as urban traffic, combustion fumes from diesel engines, home heating systems and emissions of PAHs from petrochemical factories and gas and coal combustion in power stations [18]. The smoking of tobacco is confirmed, among exposed to vehicular traffic, to be an important additional factor of increase of urinary excretion of 1-OHPu [1]. However, the contribution to the increase of global dose due to eight working hours is not negligible, due to the accumulation characteristics demonstrated by PAHs. Urinary excretion of 1-OHPu, as an indicator of internal dose of PAHs, proves to be not only an indicator of recent exposure, but also of accumulation in the past. It can be used as a signal to identify the groups at greatest risk, although its proved photochemical mutagenic effect is not considered to be specific for genotoxicity, as for 3-OHBaP [11]. However, it can be anyway considered as the best indicator of internal dose for exposure to PAHs for several categories of persons $[12,13]$, taking also into account that Pyr is much more soluble in water and able to pass through the lung to blood and undergo biotransformation with respect to Bap [16,24] Urinary excretion of $1-\mathrm{OHPu}$, as an indicator of the internal dose exposure to fumes from 
diesel engine combustion and to other environmental pollutants in areas where the production of PAHs is due to the operation of coalfired power stations, lime furnaces, combustion of part of olive trees, petrochemical candles involves a careful evaluation of the risk factors in the context of the working procedure of street sweepers. The prevention of this kind of risk might be reduced by the use of electric and/or natural gas fuelled cars especially in waste sorting house by house.

The evidence of a greater concentration in bronchitic men ask for experimental studies to test the ability of Pyr to remain in the epithelium and in sub-bronchial epithelium, apparently to a greater extent, for greater dilution in the inflammatory process, and then to undergo a biotransformation activity slowdown in water-soluble metabolites. It establish a reserve as a pre-toxic pulmonary factor, similar to the genotoxic action of compounds like $\mathrm{BaP}$ [25] indicating accumulation phenomena well known for PAHs, since when attached to inhaled particles at the alveolar level are quickly released if placed at the surface of these particles, while associated to deeper penetration ones, like nanoparticles [26], are released more slowly [10] or involved in uptake endocytosis [27].

It could be useful to calculate the "cancer risk assessment" in our group and similar ones [28]. In this contest, the calculation of ILCR (incremental life-time cancer risk inhalation) in PAHs exposure as a factor of risk evaluation for lung cancer demonstrates a good association with 1-OHP concentration, but only for smokers with exposure after finishing work and subjects with br-obstructive impairment $\left(\mathrm{ILCR}_{\text {inhalation }}\right.$ range 5, 6-9, $13 \times 10^{-6}$ ), condition that contributes to the total risk with skin contact and ingestion [29] We are in agreement with recent study [30] about the characteristics of variability of 1- OHPu excretion in different groups of workers exposed or in people with urban or industrial pollution, but in addition to environmental and behavioral factors are to be considered as important parameters as surface, size, clustering that affect in the process of uptake, intake and biotransformation in different types of atmospheric particulate in much part of nanoparticle size.

\section{Conclusions}

The possibility of implementing prevention is based on simple and effective principles and on the utilization of useful methods. In our case, the street sweepers in the performance of their work are exposed to a mixture of PAHs of some carcinogenic action. In the grading of risk, this exposure appears to be important, in addition to traditional influencing factors such as the time of exposure, cigarette smoking, food intake and the effects of accumulation within the working day, associated also to possible respiratory diseases. The $1-\mathrm{OHP}_{u}$ urinary concentration test appears useful to identify groups of persons exposed to greater risk of carcinogenicity. It is also a biological indicator of exposure to Benzo[a] pyrene, which among the PAHs is the most dangerous agent, according to ILCR values (ILCR ${ }_{\text {inhaltion }}$ range 5, 6-9, $13 \times 10^{-6}$ ), and accumulates in the body. Jongeneelen (1992), proposed an occupancy limit of 1-OHP urinary concentration of $2.3 \mu \mathrm{mol} / \mathrm{mol}$ creat for an environmental concentration of $2 \mu \mathrm{g} / \mathrm{m}^{3}$. Further studies on the concentrations in air show that Pyr values of $49 \mathrm{ng} / \mathrm{m}^{3}$ corresponding to $0.85 \mathrm{ng} / \mathrm{ml}$, with considerable lowering of values [31].

The findings of the present study are linked to the beginnings of toxicology involving chimney sweeps, namely the early work by Sir Percival Potts in the late 1770s. His work contributed to the emerging science of epidemiology as well as toxicology and lead to one of the first public health laws in Europe, namely the Chimney Sweepers Act of 1788 .

We believe that further results in the analysis of the permissible limits of carcinogenic risk, waiting for epidemiological projections, often late in terms of prevention, are key to the reduction of the negative effects, DNA damage and the development of cancer.

\section{Conflict of interest}

The authors declare no conflict of interest

\section{References}

1. Chuang CY, Chang CC (2007) Urinary 1-hydroxypyrene level relative to vehicle exhaust exposure mediated by metabolic enzyme polymorphisms. J Occup Health 49: 140-151

2. Sciarra G (2003) [Environmental and biological reference values of aromatic polycyclic hydrocarbons]. G Ital Med Lav Ergon 25: 83-93.

3. (1983) Evaluation of the carcinogenic risk of chemicals to humans Polynuclear Aromatic Compounds. Part 1, Chemical, environmental and experimental data. International Agency for Research on Cancer, Lyon 32.

4. Henkler F, Tralau T, Tentschert J, Kneuer C, Haase A, et al. (2012) Risk assessment of nanomaterials in cosmetics: a European union perspective. Arch Toxicol 86: 1641-1646.

5. Seto H1, Ohkubo T, Kanoh T, Koike M, Nakamura K, et al. (1993) Determination of polycyclic aromatic hydrocarbons in the lung. Arch Environ Contam Toxicol 24: 498-503.

6. Wenzl T, Simon R, KleinerJ, Anklam E (2006) Analytical methods for PAH polycyclicaromatic (PAHs) in food and the environment needed for new food legislation in the European Union. Trends in Analytical Chemistry 25: 716725.

7. Chien YC, Yeh CT (2010) Amounts and proportion of administered pyrene dose excreted as urinary 1-hydroxypyrene after dietaryexposure to polycyclic aromatic hydrocarbons. Arch Toxicol 84: 767-776.

8. Nerurkar PV, Okinaka L, Aoki C, Seifried, Lum-Jones, et al. (2000) CYP1A1, GSTM1, GSTP1 and genetic polymorphisms and urinary 1-hydroxypyrene excretion in non-occupationally exposed individuals. Cancer Epidemiol Biomarkers Prev 9: 1119-22.

9. Warholm AK, Carstensen U, Axmon A, Hagmar L, Levin JO, Östman A. Rannugh CYP1A1 and GSTM1 polymorphisms affect urinary 1-hydroxypyrene levels after PAH exposure Oxford Journals Life Sciences \& Medicine Carcinogenesis Volume 21, issue 4 pp. 669-676 1999

10. Gerde P, Muggenburg BA, Lundborg M, Dahl AR (2001) The rapid absorption of alveolar diesel soot-adsorbed benzo [a] pyrene: bioavailability, metabolism and dosimetry of an inhaled particle-borne carcinogen. Carcinogenesis 22: 741-749.

11. Viau C, Bouchard M, Marie-Desvergne C, Maître A (2010) Toxicokinetic considerations in using a suite of markers to better understand occupational health risk from $\mathrm{PAH}$ exposure.

12. Lee MS, Eum KD, Zoh KD, Kim TS, Pak YS, et al. (2007) Hydroxypyrene as a biomarker of $\mathrm{PAH}$ exposure among subjects living in two regions separated from a steel mill. Int Arch Occup Environ Health 80: 671-678.

13. Sánchez-Guerra M, Pelallo-Martínez N, Díaz-Barriga $F$, Carrizales-Yañez $\mathrm{L}$, Oropeza-Hernández L, et al. (2010) Urinary 1-OHP levels in children are modulated by CYP1A1, CYP1B1 * $2 \mathrm{c}{ }^{*} 3,{ }^{*} 0$ and GSTM1 NQO1 * polymorphisms.

14. Rihs HP, Spickenheuer A, Heinze E, Pesch B, Raulf-Heimsoth M, et al (2011) Modulation of urinary polycyclic aromatic hydrocarbon metabolites by enzyme polymorphisms in workers of the German Human Bitumen Study. Arch Toxicol 85: S73-S79.

15. Yan J, Wang L, Fu PP, Yu H (2004) Photomutagenicity of 16 polycyclic aromatic hydrocarbons from the US EPA priority pollutant list. Mutat Res 557: 99-108.

16. Jongeneelen F, ten Berge W (2012) Simulation of urinary excretion of 1-hydroxypyrene in various scenarios of exposure to polycyclic aromatic hydrocarbons with a generic, cross-chemical predictive PBTK-model. Int Arch Occup Environ Health 85: 689-702.

17. (2000) WHO Library Air quality guidelines for Europe ; second edition. WHO regional publications, European series 91: 92-94.

18. Merlo F, Andreassen A, Weston A, Pan CF, et al. (1998) Urinary Excretion of 1-hydroxypyrene as a Marker for Exposure to Urban Air Levels of Pah By Aromatic. Cancer Epidemiol Biomarkers Prev 7: 147-55.

19. Jongeneelen FJ, Anzion RB, Henderson PT (1987) Determination of hydroxylated metabolites of polycyclic aromatic hydrocarbons in urine. J Chromatogr 413: 227-232.

20. Liao CM, Chiang KC (2006) Probabilistic risk assessment for personal exposure to carcinogenic polycyclic aromatic hydrocarbons in Taiwanese temples. Chemosphere 63: 1610-1619.

21. Chen SC, Liao CM (2006) Health risk assessment on human exposed to environmental polycyclic aromatic hydrocarbons pollution sources. Sci Total Environ 366: 112-123.

22. Watanabe KH, Djordjevic MV, Stellman SD, Toccalino PL, Austin DF, et al. (2009) Incremental Lifetime Cancer Risks Computed for Benzo[a]pyrene and Two Tobacco-Specific N-nitrosamines in Mainstream Cigarette Smoke Compared with Lung Cancer Risks Derived from Epidemiologic Data Regul Toxicol Pharmacol 55: 123-133. 
23. Environmental Health Division, Environmental Surveillance and Assessmen Section PO Box 64975 St. Paul, MN 55164-0975 651-201-5000 www.health. state.mn.us Guidance for Evaluating the Cancer Potency of Polycyclic Aromatic Hydrocarbon (PAH) Mixtures in Environmental Samples Minnesota Department of Health August 15, 2013

24. Jongeneelen FJ (2001) Benchmark guideline for urinary 1-hydroxypyrene as biomarker of occupational exposure to polycyclic aromatic hydrocarbons. Ann Occup Hyg 45: 3-13.

25. Gerde P, Muggenburg BA, Scott GG, Lewis JL, Pyon KH, et al. (1998) Loca metabolism in lung airways increases the uncertainty of pyrene as a biomarker of exposure by aromatic hydrocarbon. Carcinogenesis 19: 493-500.

26. Dobbins RA. (2007) Hydrocarbon Nanoparticles Formed in Flames and Diesel Engines. Aerosol Science and Technology 41:485-496.

27. Mazzotta M, Mazzotta AD, Fernández M, Tamborino B, De Filippis G
(2012) [New toxicological patterns of nanomaterials, nanostructures and nanoparticles]. G Ital Med Lav Ergon 34: 667-670.

28. Boström CE, Gerde P, Hanberg A, Jernström B, Johansson C, et al. (2002) Cancer risk assessment, indicators and guidelines for polycyclic aromatic hydrocarbons in the ambient air. Environ Health Perspect 110: 451-488.

29. Yang Q, Chen H, Li B (2015) Polycyclic Aromatic Hydrocarbons (PAHs) in Indoor Dusts of Guizhou, Southwest of China: Status, Sources and Potential Human Health Risk. PLoS One 10: e0118141.

30. Ciarrocca M, Rosati MV, Tomei F, Capozzella A, Andreozzi G, et al. (2014) Is urinary 1-hydroxypyrene a valid biomarker for exposure to air pollution in outdoor workers? A meta-analysis. J Expo Sci Environ Epidemiol 24: 17-26.

31. (2009) Urinary 1-hydroxypyrene in nonsmokers : a biomarker for coke smoke exposure and general urban PAH exposure by In-Kyu Han edition 4World Cat. 